\title{
Comparison of the usage habits of healthcare systems of the imigrants and local residents
}

\author{
Umut Payza ${ }^{\mathrm{a}, *}$, Zeynep Karakaya ${ }^{\mathrm{a}}$ Fatih Esad Topal ${ }^{\mathrm{a}}$, Serkan Bilgin ${ }^{\mathrm{b}}$, Ahmet Kayal1 ${ }^{\mathrm{a}}$, Ecem Ermete \\ a Katip Celebi University Atatürk Traning and Research Hospital, Department of Emergency, TR-35360, İzmir Turkey \\ b Batman Regional State Hospital, Department of Emergency, TR-72000, Batman Turkey
}

\section{ART I C LE IN F O}

\section{Article history:}

Received 26 June 2019

Received in revised form 05 August 2019

Accepted 09 September 2019

\section{Keywords:}

Imigrants

Residents

Health Policy

\begin{abstract}
A B S T R A C T
Turkey is one of the most popular immigration countries because of the wars that are ongoing in its southern border and its location on access routes to Europe. Migrations continue because of wars and political turmoil. The increasing number of migrants requires revising the public healthcare planning. In our study, we compared the behaviors of immigrants and local people. We examined to which extent immigrants used the clinics of our hospital. We interpreted the adequacy of the current healthcare system for migrants. We analyzed the hospital admissions of migrants and local residents who applied to our hospital between January 2014 and December 2018 in retrospective fashion. We determined the rates of referral to clinics. We determined that the highest referral rates of the migrants were made to emergency services, gynecology and obstetrics. We observed that the birth rates increased in migrants in the following period. However, despite the traumas, immigrants did not use psychiatric units. The existing healthcare and social policies must be revised by considering especially the needs of immigrants and their use of healthcare systems. We believe that primary healthcare services must be delivered equally to all individuals to reduce the intensity of emergency services, gynecology and obstetrics departments, and pediatric services. We also believe that the trauma that iscaused by immigration must not be underestimated.
\end{abstract}

(C) 2019. Turkish Journal Park Academic. All rights reserved.

\section{Introduction}

People who migrate to countries other than their country of origin due to wars, terror, political conflicts or similar reasons to improve their financial or social situation and increase their expectations are called as refugees or migrants. Asylum-migrations have always been experienced throughout human history. Hunger, natural disasters and wars are the most frequent causes.

Turkey has received immigration throughout its history because of its location and the wars in countries surrounding it. In recent years, a serious migration wave because of the war in Iraq and Syria has started. The number of registered immigrants was 37.710 in 2013. This figure was 4.9 million in February 2019 (1). The actual target for migration of the immigrant population in Turkey is Europe (2). This number of migrants will affect both the social/healthcare policies of target countries and their economic systems.
One of the most affected systems because of irregular and intense migrations is the healthcare system. Possible damage in healthcare services may be avoided by examining the habits of migrants in using the healthcare system. Comparing the outcomes with the behaviors of the resident people will show us whether or not the current system is a suitable model. In addition, the needs of the immigrants will also be examined in this respect, and their changing needs will be determined.

\section{Patients and Methods}

\section{Study design}

This is a descriptive study. Our study was conducted in Izmir Katip Çelebi University, Atatürk Training and Research Hospital. The 5-year period between 2014 and 2018 was examined in retrospective fashion. The applications to all units of our hospital and emergency department were

\footnotetext{
* Corresponding author:

E-mail address: umutpayza@hotmail.com
} 
determined. Two groups were formed as Republic of Turkey citizens and immigrants. The demographic characteristics of the patients were recorded, and references to all clinics in our hospital were compared.

Ethical approval was received for the study from the Ethics Board of our hospital.

\subsection{Patients and setting}

The applications of all age groups were included in the study. The patients who were accepted as Red Code and those who underwent emergency intervention and cardiopulmonary resuscitation were excluded. The patients whose data could not be determined or whose nationality could not be determined were not included in the present study.

\subsection{Data collection}

The patients who applied to our hospital between 2014 and 2018 were screened in our hospital database. The annual data were recorded. The clinical manifestations and demographic characteristics of the patients who met the inclusion criteria were determined.

\subsection{Statistical analysis}

The data were evaluated in the IBM SPSS Statistics 25.0 statistical package program (IBM Corp. released in 2017. IBM SPSS Statistics for Windows, Version 25.0. Armonk, NY: IBM Corp.). As the descriptive statistics, number of units $(n)$ and percentage (\%) were given.

The number and rates of admissions were compared with each other according to the clinics. Also, the numbers and rates of hospital admissions were compared between immigrants and residents.

\section{Results}

When the applications were examined, it was determined that the number of the patients who were the citizens of the Republic of Turkey in 5 years was 10.129.060. The male-tofemale rate was $1 / 1.3$. The average age of all patients was $66 \pm 2$. The average age of the women was $49 \pm 3$ years. The average age of the males was $68 \pm 4$ years.

The number of the refugees who applied to our hospital was 68.444 . The average age of the refugees was 26 , and the average age of the women was $22 \pm 1.2$. The average age of the males was $29 \pm 0.5$. The male-to-female rate was $1 / 1.6$.

When compared between years, the application numbers are shown in Table 1 and Table 2.

Table 1. Application rates to services by years (\%)

\begin{tabular}{|c|c|c|c|c|c|c|c|c|c|c|}
\hline \multirow{2}{*}{$\begin{array}{l}\text { YEAR } \\
\text { /CLINICAL }\end{array}$} & \multicolumn{2}{|c|}{2014} & \multicolumn{2}{|c|}{2015} & \multicolumn{2}{|c|}{2016} & \multicolumn{2}{|c|}{2017} & \multicolumn{2}{|c|}{2018} \\
\hline & $\begin{array}{c}\mathbf{R} \\
\%\end{array}$ & $\begin{array}{l}\mathbf{I} \\
\%\end{array}$ & $\begin{array}{l}\mathbf{R} \\
\%\end{array}$ & $\begin{array}{l}\mathbf{I} \\
\%\end{array}$ & $\begin{array}{l}\mathbf{R} \\
\%\end{array}$ & $\begin{array}{l}\mathbf{I} \\
\%\end{array}$ & $\begin{array}{l}\mathbf{R} \\
\%\end{array}$ & $\begin{array}{l}\dot{\mathbf{I}} \\
\%\end{array}$ & $\begin{array}{l}\mathbf{R} \\
\%\end{array}$ & $\begin{array}{l}\mathbf{I} \\
\%\end{array}$ \\
\hline E.R. & 13 & 32 & 14 & 37 & 12 & 38 & 11 & 38 & 11 & 32 \\
\hline $\begin{array}{l}\text { Primary } \\
\text { care }\end{array}$ & 2 & 0 & 2 & 1 & 2 & 1 & 2 & 2 & 2 & 1 \\
\hline $\begin{array}{l}\text { Brain } \\
\text { Surgery }\end{array}$ & 2 & 1 & 2 & 2 & 2 & 1 & 2 & 2 & 2 & 2 \\
\hline $\begin{array}{l}\text { Child } \\
\text { Health }\end{array}$ & 2 & 2 & 2 & 1 & 2 & 3 & 2 & 3 & 3 & 4 \\
\hline $\begin{array}{l}\text { Skin } \\
\text { Diseases }\end{array}$ & 5 & 6 & 5 & 5 & 5 & 4 & 4 & 3 & 4 & 3 \\
\hline Dental & 3 & 4 & 3 & 2 & 3 & 2 & 3 & 1 & 2 & 1 \\
\hline Endocrin & 3 & 1 & 3 & 1 & 3 & 1 & 3 & 1 & 2 & 1 \\
\hline PMR & 4 & 3 & 4 & 2 & 4 & 4 & 5 & 4 & 5 & 3 \\
\hline $\begin{array}{l}\begin{array}{l}\text { Gastro- } \\
\text { enterology }\end{array}\end{array}$ & 3 & 2 & 3 & 2 & 3 & 2 & 3 & 2 & 3 & 2 \\
\hline $\begin{array}{l}\text { General } \\
\text { Surgery }\end{array}$ & 4 & 1 & 4 & 2 & 5 & 2 & 5 & 2 & 5 & 2 \\
\hline $\begin{array}{l}\text { Chest } \\
\text { Diseases }\end{array}$ & 4 & 1 & 3 & 1 & 3 & 2 & 3 & 1 & 3 & 1 \\
\hline $\begin{array}{l}\text { Eye } \\
\text { diseases }\end{array}$ & 4 & 4 & 4 & 2 & 4 & 3 & 4 & 2 & 5 & 3 \\
\hline $\begin{array}{l}\text { Internal } \\
\text { diseases }\end{array}$ & 8 & 5 & 7 & 4 & 8 & 2 & 9 & 3 & 9 & 4 \\
\hline Gynecology & 5 & 13 & 4 & 12 & 4 & 9 & 4 & 7 & 4 & 9 \\
\hline $\begin{array}{l}\text { Cardiac } \\
\text { surgery }\end{array}$ & 2 & 1 & 2 & 2 & 2 & 1 & 2 & 2 & 2 & 2 \\
\hline Cardiology & 4 & 3 & 4 & 3 & 4 & 4 & 5 & 3 & 4 & 3 \\
\hline E.N.T. & 5 & 3 & 5 & 2 & 5 & 3 & 5 & 4 & 5 & 3 \\
\hline neurology & 5 & 2 & 5 & 3 & 5 & 6 & 5 & 6 & 5 & 8 \\
\hline orthopedics & 4 & 4 & 4 & 6 & 4 & 4 & 5 & 5 & 5 & 6 \\
\hline $\begin{array}{l}\text { Plastic } \\
\text { surgery }\end{array}$ & 1 & 1 & 1 & 1 & 1 & 1 & 1 & 1 & 1 & 1 \\
\hline psychiatry & 4 & 0 & 4 & 0 & 3 & 0 & 3 & 0 & 4 & 0 \\
\hline Urology & 4 & 3 & 4 & 4 & 4 & 3 & 4 & 3 & 4 & 3 \\
\hline Total (N) & $\begin{array}{l}\overrightarrow{\dot{H}} \\
\stackrel{0}{\sigma}\end{array}$ & 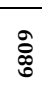 & $\vec{\sigma}$ & న్న & $\tilde{\sigma}$ & $\stackrel{\breve{\omega}}{\Delta}$ & $\begin{array}{l}\tilde{E} \\
\dot{\theta}\end{array}$ & $\begin{array}{l}\vec{y} \\
\text { Ñ } \\
\text { D. }\end{array}$ & $\begin{array}{l}\tilde{E} \\
\dot{\theta}\end{array}$ & 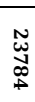 \\
\hline
\end{tabular}

${ }^{*} \mathbf{b}=$ billion, ${ }^{*}$ E.R. $=$ emergency room, ${ }^{*}$ E.N.T. $=$ Ear, Nose and Throat Diseases, ${ }^{*} \mathbf{I}=$ Immigrants $* \mathbf{R}=$ residents $* \mathbf{P M R}=$ Physical Medicine and Rehabilitation

When the applications to all clinics were examined, the rate of emergency services usage of the refugees was higher at a significant level than that of the local people. It was determined that one in three patients used emergency 
services within an average of 5 years.

The use of gynecology service and delivery unit was higher at a significant level $(\mathrm{p}<0.05)$. It was determined that the applications were made for pregnancy follow-up and delivery with a high rate. The birth rate of the immigrants was $14.3 \%$ in our hospital. The birth rate of the local people was $0.8 \%$. The birth rate of immigrants was higher at a statistical level compared to the local people. A statistically significant increase was detected in the pediatric outpatient visits of the refugees as of the year $2016(\mathrm{p}<0.005)$. When the applications made to internal diseases clinics were examined, it was determined that the number of applications by refugees was lower at a significant level $(\mathrm{p}<0.05)$. When the psychiatric applications were evaluated in a retrospective way, it was found that there were statistically significant decreases $(\mathrm{p}<0.00)$.

Table 2. Comparison of the using the clinics by residents and immigrants; average rates for 5 years

\begin{tabular}{|c|c|c|}
\hline \multirow[b]{2}{*}{ CLINICAL / YEAR } & \multicolumn{2}{|c|}{ Total } \\
\hline & $\mathbf{R}(\%)$ & İ $(\%)$ \\
\hline E.R. & 12 & 35 \\
\hline Primary care & 2 & 1 \\
\hline Brain Surgery & 2 & 2 \\
\hline Child Health & 2 & 3 \\
\hline Skin Diseases & 5 & 4 \\
\hline Dental Polyclinic & 3 & 2 \\
\hline Endocrin & 3 & 1 \\
\hline PMR & 4 & 4 \\
\hline Gastroenterology & 3 & 2 \\
\hline General Surgery & 5 & 2 \\
\hline Chest Diseases & 3 & 1 \\
\hline Eye diseases & 4 & 3 \\
\hline Internal diseases & 8 & 4 \\
\hline Gynecology & 4 & 9 \\
\hline Cardiac surgery & 2 & 2 \\
\hline Cardiology & 4 & 3 \\
\hline E.N.T. & 5 & 3 \\
\hline neurology & 5 & 6 \\
\hline orthopedics & 5 & 5 \\
\hline Plastic surgery & 1 & 1 \\
\hline psychiatry & 4 & 0 \\
\hline Urology & 4 & 3 \\
\hline Total (n) & $10 \mathbf{b}$ & 68444 \\
\hline
\end{tabular}

${ }^{*} \mathbf{b}=$ billion, ${ }^{*}$ E.R. $=$ emergency room, ${ }^{*}$ E.N.T.= Ear, Nose and Throat
Diseases, $* \dot{\mathbf{I}}=$ Immigrants $* \mathbf{R}=$ residents $* \mathbf{P M R}=$ Physical Medicine and Rehabilitation

\section{Discussion}

Ibn Khaldun, the 14th-century thinker of sociology and the pioneer of economics, said, "Geography is destiny". The war, which started in Iraq and Syria in 2003, started a great migration wave. Turkey hosts 4.9 million refugees, including Syrians refugees who are close to 4 million. Turkey is the transit route for immigrants who want to travel to the European continent. Turkey continues to work to prevent the illegal transition to European countries by irregular migrants.

This high degree of immigration affects the social and healthcare policies in areas where immigrants live in intense numbers. Especially the healthcare system is affected by migration. Evaluating the use of healthcare systems of immigrants will ensure that healthcare policies are replanned for continuing migrations. There are few data on health status of immigrants. Our study was conducted in Izmir, which is one of the destinations where immigrants most frequently immigrate, and illegal escapes to Europe are most common. According to the data of Republic of Turkey, Ministry of Interior, General Directorate of Immigration Administration, Izmir is the $8^{\text {th }}$ city that received the highest number of immigrants in Turkey. However, Izmir is the second city following Istanbul, where the transitions to Europe are made (1). In our study, the habits of using the healthcare system by the patients living in the area and the habits of refugees were compared. In this way, we targeted to examine the effects of refugees on healthcare systems. In our study, the data of 2 million patients on an annual scale were analyzed in retrospective fashion. The nationalities of these patients were recorded. The clinics they applied were also determined. When the database was examined, it was determined that the most frequently referred clinic was the emergency department in our hospital. Although the number of applicants varied, their rates were high. In a study conducted by Russo et al. in Italy, it was reported that immigrants with cardiac diseases used emergency services more intensively. In addition, Chan T. C. et al. reported in his study that irregular immigrants prefer emergency health services to receive healthcare. In both studies, especially irregular immigrants, the reason for the excessive use of emergency services was determined that immigrants did not receive adequate general medical support, they had problems in terms of insurance systems, and not being able to benefit from the prescription $(3,4)$. On the other hand, Andrea Buron et al. stated in his study that the rate of nonSpanish immigrants to emergency services was low when compared to the local people. They also stated that the 
reason for the use of primary healthcare services less by immigrants was that they wanted to use primary healthcare services equally (5). These studies show that irregular migration increases the workload of the emergency healthcare services. Similar negative outcomes were faced when healthcare services were not planned according to immigrants, and equal access to these services was not given. In case the planned and primary services are provided to everybody, there will be no emergency service intensity. In addition, the statistically significant low level of applications to internal diseases departments was due to the limitation to healthcare services, and ensuring access to these services in emergency services.

In our study, the second clinic with the most clinical presentations was the gynecology and obstetrics units. When the initial diagnoses of the patients were examined, it was determined that the pregnancy and delivery applications were high. When birth rates were compared, it was determined that the average birth rate was $14.3 \%$ in immigrants, and was $0.8 \%$ in the native population. When compared to the native population, this rate is significantly higher. In the study of Camarota and Zeigler, too, the rate of birth of migrants was higher at a statistical level than that of the local people, and supports our study. However, it is also noteworthy that there were rapid and statistical increase in the rates of referrals to pediatric clinic (6). The high birth rates determined in our study led to an increase in pediatric applications in the following years. The important point for the community and minority health is that there will be high rates, in births, in pregnancy complications, in newborn diseases/deaths, and in child infections. Mary M. Reed et al. pointed out to this danger (7). For this reason, more effective planning must be made in national healthcare policies and vaccination. The epidemic risk must be decreased by providing vaccination and general healthcare services. When the applications were analyzed according to the years, it was determined that the service that received the least number of applications was psychiatric clinic. There were years when psychiatric applications were not made despite the increase in the number of migrants. J. David Kinzie conducted a study and reported that patients with psychiatric disorders also migrate, and that migration triggered the existing psycho-pathologies. More importantly, he also pointed out that there was a large population who experienced a traumatic migration like hunger, war, refugee camps. He emphasized that the psychosocial traumas experienced by a large number of immigrants could not be treated after these processes (8). Kirmayer et al. conducted a study and argued that the negative effects of the psychiatric disorders and the post-traumatic processes caused by immigration prevented the integration of immigrants to the society. He also pointed out to the deterioration in the familial and social structure (9). In both studies, the reason for this problem is claimed to be the language barrier and cultural differences. For this reason, it is necessary to solve communication problems while healthcare plans are made; and social policies that support healthcare policies must be planned.

\section{Limitations}

Although our study was conducted in a region with high migration, it was a single-center study. It must be supported by multicenter studies with similar numbers of immigrants. The patients who lived in our region, but did not have any identities were excluded from the study.

\section{Conclusion}

Migration will occur as long as wars and hungers continue. Especially irregular migrations affect every society. The solution of the problems that will be faced may be prevented by knowing the effects of immigration. For this reason, we believe that studies conducted on immigrants are important. The negative effects of immigration on healthcare systems may be avoided by making the primary healthcare services effective and accessible. In addition, primary healthcare services must be supported through psycho-social support programs. Language barrier and communication problems must be solved. When the current figures are considered, our study has a very high participation rate. We believe that the results concluded in it are valuable.

\section{References:}

1. General Directorate of Migration Management. http://www.goc.gov.tr

2. Cummings C.,\& Pacitto J., Why People Move: Understanding the Drivers and Trends of Migration to Europe., 12.28.2015 http://www.odi.org

3. Russo V., Santarelli S., Magrini L., et al. Multicentre Italian analysis on cardiovascular diseases: impact of immigrants referral to emergency department, Journal of Cardiovascular Medicine, Volume18, Number 3.March.2017,Doi: https://doi.org/10.2459/JCM.0000000000 000221

4. Chan TC, Krishel SJ, Bramwell Kj, Clark RF: Survey of illegal immigrants seen in an emergency department. West J Med 1996; 164:212-216

5. Andrea B., Francesc C., Oscar G.; Oriol Vall and Xavier Castells Hospital emergency department utilisation rates among the immigrant population in Barcelona, Spain BMC Health Services Research 2008, 8:51 http://www.biomedcentral.com/1472 $6963 / 8 / 51$

6. Steven A., Zeigler C., Zeigler K.; The Declining Fertility of Immigrants and Natives. Centre for Immigrants Studies, 
September 2017 http://cis.org/declining-fertility. Google Scholar

7. Mary M R.John M W., Caroline B., Catherine B., Fickenscher A.; Birth outcomes in Colorado's undocumented immigrant population BMC Public; Health: 20055: 100 https://doi.org/10.1186/1471-2458-5-100

8. J. D. Kinzie, Immigrants and Refugees: The Psychiatric Perspective. Published; December.1.2006, Research Art. https://doi.org/10.1177/1363461506070782

9. Laurence J. Kirmayer, MD, Lavanya Narasiah, MD MSc, Marie Munoz, et al. MCISc, for the Canadian Collaboration for Immigrant and Refugee Health (CCIRH). Common mental health problems in immigrants and refugees: general approach in primary care, CMAJ. 2011 Sep 6; 183(12): E959-E967. PMCID: PMC3168672 doi: 10.1503/cmaj.090292 